\title{
Smoking and lung cancer risk in Sri Lankan men: a case-control study
}

\author{
P U Chulasiri ${ }^{1}$, N S Gunawardana ${ }^{2}$, A de Silva ${ }^{3}$
}

(Index words: tobacco, smoking, ever smoker, lung cancer, odds ratio)

\begin{abstract}
Objectives Tobacco smoking is the strongest risk factor for lung cancer. As the strength of association of smoking and lung cancer in Sri Lanka has not been estimated, a study was conducted to estimate the risk of lung cancer among adult male smokers in the Colombo District.

Methods A case control study was carried out among 62 newly diagnosed male lung cancer patients from the Colombo District presenting to National Cancer Institute, Maharagama. Four controls per case were randomly selected from the same Grama Niladhari area matching the age of the cases within 10 years. Absence of lung cancer was clinically confirmed in the controls. Information on smoking, other potential risk factors and confounders were obtained using an interviewer-administered questionnaire. Univariate analysis and logistic regression identified the risk factors.
\end{abstract}

Results After adjustment for confounding variables, ever smokers odds of having lung cancer compared to never smokers OR 10.74 (95\% Cl 3.54-32.59). Lower educ ation level (OR=5.61, 95\% Cl 2.37-13.28), ever exposed to X-rays (OR=2.81, 95\% Cl 1.14-6.94) and a family history of any cancer (OR=2.83, 95\% Cl 1.09-7.30) were other significant risk factors. The population attributable risk percent (PAR\%) showed that $84.04 \%$ of the male lung cancer cases are attributed to smoking.

Conclusions Smoking and exposure to X-rays were risk factor for lung cancer among adult males in the Colombo District.

Ceylon Medical Journal 2017; 62: 25-28

DOI: http://doi.org/10.4038/cmj.v62i1.8429

\section{Introduction}

Non-communicable diseases (NCD) are a leading cause of death globally. Tobacco smoking is associated with ill-health, disability and an increased risk of death from communicable diseases [1]. Tobacco has been named as the only 'legal drug' that kills its users when used exactly as intended by manufacturers [1]. Cigarettes are the commonest form of smoked tobacco in the world [1].

According to data from the National Cancer Registry of Sri Lanka, the second commonest cancer among males was lung cancer (8.6 per 100,000 population), it was the sixth commonest cancer among all Sri Lankans (5.4 per 100,000 population) [2].

Risk factors for lung cancer are well established. They include active and passive tobacco smoking, exposure to asbestos, radon gas or wood smoke, familial and genetic factors and exposure to indoor and outdoor air pollution [3-4]. Among these risk factors, cigarette smoking is the strongest determinant of lung cancer [5].

The risk of lung cancer in Asian countries is five times higher among smokers compared to non-smokers $[6,7]$. The strength of the association of lung cancer and smoking in Sri Lanka has not been assessed in the past. It is likely that the range of risk factors for lung cancer in Sri Lanka are different and the magnitude of risk due to smoking in the Sri Lankan populations is unknown. Establishing the strength of the association is the first step in identifying attributable risk and population attributable risk of tobacco smoking in lung cancer. This data is important to plan tobacco prevention activities in the country. Thus, the present study was undertaken to estimate the strength of the association between tobacco smoking and lung cancer and the population attributable risk of tobacco smoking on lung cancer among adult males in Sri Lanka.

${ }^{1}$ Ministry of Health, Sri Lanka, ${ }^{2}$ Department of Community Medicine, Faculty of Medicine, and ${ }^{3}$ Department of Economics, Faculty of Arts, University of Colombo, Sri Lanka.

Correspondence: PUC, e-mail: <pubudu.chulasiri@gmail.com>. Received 30 May 2016 and revised version accepted 25 August 2016.

This is an open-access article distributed under the terms of the Creative Commons Attribution License, which permits unrestricted use, distribution, and reproduction in any medium, provided the original author and source are credited. 


\section{Methods}

A case control study was carried out to identify the risk factors of lung cancer among adult men in the Colombo District. Male patients with primary lung cancer, aged more than 20 years, resident in the Colombo district, diagnosed within the last six months and treated at the National Cancer Institute, Maharagama (CIM) were included in the study. Diagnosis was confirmed by an Oncologist. The controls were adult males aged $>20$ years selected from the community using the voters list as the sampling frame. Lung cancer was excluded in controls by clinical history and examination. The controls were matched by age and area of residence. Four controls per case who were aged within 10 years of a case were randomly selected from the same Grama Niladhari (GN) area.

The sample size was calculated using the formula for multiple controls per case. The rate of smoking among controls was taken as $38 \%$ based on smoking prevalence in Sri Lanka [8]. Odds ratio associated with the exposure (smoking) was taken as 2.7 [9]. By accounting for a possible $10 \%$ non-response rate, the number of cases selected was 62 and based on a case to control ratio of 1:4, the number of controls included in the study was 248 .

An interviewer-administered questionnaire was used to assess risk factors of lung cancer. The same questionnaire was used in both cases and controls. The risk factors included were smoking, exposure to second hand smoking (SHS), alcohol consumption, dietary habits, occupational exposure, household indoor air pollution, exposure to radiation and history of cancers in the family. Categorisation of smokers was based on the definitions by the Centre for Disease Control (CDC), Atlanta, United States [10].

The smokers were categorised as ‘ever smokers’ and 'never smokers'. Persons who had not smoked a tobacco product (cigarette, cigar, bidi, pipe) or had smoked fewer than 100 in their lifetime were classified as 'never smokers' and those who had smoked more than 100 tobacco products in their lifetime were classified as 'ever smokers'. Ever smokers were categorised into 'current smokers' and 'former smokers'. Ever smokers who were currently smoking tobacco products daily or on some days were classified as ‘current smokers' (daily or nondaily) and those who had not smoking tobacco products during the last 30 days but had previously smoked daily or on some days were classified as 'former smokers' (daily or non-daily).

SHS was defined as breathing tobacco smoke emitted by someone at home, boarding house, inside a vehicle or inside a closed public area (cinema hall, cafeteria, shop, public place) during the lifetime.

Beverages that contain ethyl alcohol (arrack, wine, brandy, beer, toddy, kasippu etc) were considered as alcohol. Classification of drinkers into lifetime abstainer, former regular drinker, current drinker and non-drinker was based on CDC guidelines.

Four pre-intern medical officers were trained as data collectors. Data entry was carried out using Epidata software (version 3.1). Statistical analyses were conducted using SPSS version 20. Variables considered as potential risk factors were stratified into two levels. Initially, the risk factors for lung cancer were identified using bivariate cross tabulations and by calculating the odds ratios (OR) and 95\% confidence intervals (CI). Statistical significance for the association was calculated based on the chi-square test, and $p<0.05$ was considered as statistically significant. Multivariate logistic regression analysis was carried out to identify the adjusted ORs. Independent variables used for the analyses were variables with a $p<0.2$ in the bivariate analysis of OR. Approval was obtained from the Ethics Review Committee (ERC) of Faculty of Medicine, University of Colombo. Written informed consent was obtained from all patients.

\section{Results}

All 62 eligible cases who were invited, participated in the study. The study included 246 eligible controls out of 248 with a response rate of 99.2\%.

A majority of the cases $(n=28,45.2 \%)$ and controls $(n=110,44.7 \%)$ were aged 60-69 years and there was no significant difference in age between cases and controls.

Bivariate analyses showed that males with education less than GCE Ordinary Level had significantly higher risk, (OR=4.0; 95\% CI 2.12-7.54) compared to those who had passed GCE Ordinary Level. The risk of lung cancer among the males who had not been employed during the life time was significantly lower $(\mathrm{OR}=0.16$; 95\% CI-0.03-0.98). Religion, ethnicity or employment was not associated with lung cancer.

None of the lung cancer patients had other cancers while two controls had prostate cancer and thyroid cancer. A majority of cases $(n=61,98.4 \%)$ and controls $(n=243$, $98.8 \%$ ) had no family history of lung cancer or any other cancer ( $n=49,79 \%$ and $n=209,85.0 \%$ respectively).

The risk of lung cancer among males who had been exposed to at least one X-ray in their lifetime was significantly higher than those who had no such exposure $(\mathrm{OR}=3.45$; 95\% CI 1.83-6.51). The risk of lung cancer in those who had been exposed to at least one CT scan in their lifetime was significantly higher than those who had not (OR=5.17; 95\% CI 2.23-12.02).

The risk of lung cancer among 'ever smokers' was significantly higher compared to 'never smokers' (OR=10.01; 95\% CI-3.88-25.52). Twenty eight (45.2\%) 'ever smokers' among cases and 65 (26.4\%) 'ever smokers' among controls were 'current daily smokers'. 
A small proportion of 'ever smokers' among cases $(\mathrm{n}=2$, $3.2 \%)$ and controls ( $n=5,2.0 \%)$ current 'non-daily smokers'. Other than the former non-daily smokers, other 'ever smoker' categories (current daily, current non-daily and former daily) had higher risk of lung cancer compared to the 'never smoker' categories (current daily $\mathrm{OR}=9.9$; 95\% CI 3.65-26.9), current non-daily OR=9.20; 95\% CI 1.42-59.59) and former daily (OR=11.27; 95\% CI 4.08-31.12) (Table 1).

A majority of the cases $(n=50,80.6 \%)$ and approximately half the controls ( $n=116,52.8 \%)$ had smoked more than 100 sticks per year in their lifetime and the risk of having lung cancer was (OR=4.67; 95\% CI 2.37-9.19) higher compared to those who have smoked zero to 100 sticks per year. The risk of getting lung cancer among males who had smoked more than 20 years (OR=2.45; 95\% CI 1.37-4.39) was higher compared to those who had smoked less than 20 years or not smoked at all. Current smokers and those who had quit smoking within a period of ten years showed $\mathrm{OR}=8.8$ compared to those who had quit smoking more than ten years ago or had never smoked.

Approximately half of the cases $(n=33,53.2 \%)$ and controls ( $n=104,42.3 \%)$ reported exposure to SHS either at home, at restaurants or inside vehicles in their lifetime. When exposure to SHS in any location was considered, a majority of the cases $(n=49,79 \%)$ and controls $(n=155,63 \%)$ had been exposed to SHS. The risk of lung cancer was (OR 2.22; 95\% CI 1.10-4.47) higher among males who had been exposed to SHS at home, restaurants or vehicles compared to those without (Table 2).

After adjusting for confounding variables, four significant risk factors were identified. 'Ever smokers' had a significantly higher risk of lung cancer compared to 'never smokers' (OR=10.74; 95\% (3.54-32.59). Education $\leq$ GCE Ordinary Level (OR=5.61; 95\% CI 2.37-13.28), 'ever exposure to $\mathrm{X}$ rays' ( $\mathrm{OR}=2.81$; 95\% CI 1.14-6.94) and family history of any cancer $(\mathrm{OR}=2.83$; 95\% CI 1.09-7.30), were significant after adjustment for confounders (Table 3 ).

Population attributable risk percent (PAR\%) of smoking for lung cancer was estimated as $84.04 \%$. Prevalence of 'ever smokers' was estimated as 54.1\% (95\% CI 51.1\% - 57.0\%) based on a community-based cross sectional study while the OR of smoking and lung cancer was estimated as 10.74 [23].

Table 1. Association between smoking status and lung cancer

\begin{tabular}{|c|c|c|c|c|c|}
\hline \multirow[t]{2}{*}{ Smoking category } & \multicolumn{2}{|c|}{ Cases } & \multicolumn{2}{|c|}{ Controls } & \multirow[t]{2}{*}{ Odds Ratio (95\% CI) } \\
\hline & $N$ & $\%$ & $N$ & $\%$ & \\
\hline Ever smoker & 57 & 91.9 & 131 & 53.3 & $10.01(3.88-25.82) p<0.001$ \\
\hline Current daily & 28 & 45.2 & 65 & 26.4 & $9.9(3.65-26.9) p=0.001$ \\
\hline Current non-daily & 2 & 3.2 & 5 & 2.0 & $9.20(1.42-59.59) p=0.006$ \\
\hline Former daily & 25 & 40.3 & 51 & 20.7 & $11.27(4.08-31.12) p=0.001$ \\
\hline Former non-daily & 2 & 3.2 & 10 & 4.1 & $4.60(0.78-16.8) p=0.06$ \\
\hline Never smoked & 5 & 8.1 & 115 & 46.7 & 1.0 \\
\hline
\end{tabular}

Table 2. Association between exposure to second hand smoking and lung cancer

\begin{tabular}{|c|c|c|c|c|c|}
\hline \multirow[t]{2}{*}{ Category } & \multicolumn{2}{|c|}{ Cases } & \multicolumn{2}{|c|}{ Controls } & \multirow[t]{2}{*}{ Odds Ratio (95\% CI) } \\
\hline & $N$ & $\%$ & $N$ & $\%$ & \\
\hline $\begin{array}{l}\text { Exposed to second hand smoking } \\
\text { in home/restaurants/vehicles }\end{array}$ & 33 & 53.2 & 104 & 42.3 & $\begin{array}{l}2.22(1.10-4.47) \\
\quad \mathrm{p}=0.02\end{array}$ \\
\hline $\begin{array}{l}\text { Exposed to second hand } \\
\text { smoking in work place }\end{array}$ & 29 & 46.8 & 88 & 35.8 & $\begin{array}{l}2.30(1.13-4.72) \\
\quad \mathrm{p}=0.02\end{array}$ \\
\hline $\begin{array}{l}\text { Exposed to second hand smoking } \\
\text { in any location }\end{array}$ & 49 & 79.0 & 155 & 63.0 & $\begin{array}{l}2.21(1.14-4.30) \\
\quad \mathrm{p}=0.02\end{array}$ \\
\hline Not exposed to any SHS & 13 & 21.0 & 91 & 37.0 & 1.0 \\
\hline
\end{tabular}


Table 3. Multivariate logistic regression for the risk factors

\begin{tabular}{lcc}
\hline Variable & OR & $\begin{array}{c}95 \% \\
\text { Confidence } \\
\text { Intervals }\end{array}$ \\
\hline $\begin{array}{l}\text { Smoking status } \\
\text { Ever smoked } \\
\text { Never smoked* }\end{array}$ & 10.74 & $(3.54-32.59)$ \\
Highest Education Level & 1.0 & \\
$\quad$ Upto GCE (O/L) & \\
$\quad$ GCE O/L pass and & 5.61 & $(2.37-13.28)$ \\
above* & 1.0 & \\
Exposure to X-rays & & \\
Ever exposed \\
Never exposed* \\
Family history of cancer \\
$\quad$ Yes \\
No*
\end{tabular}

Variable(s) entered: Ever smoking status, alcohol consumption, Highest educational qualification, Employment, Family History of Cancer, exposure to X Ray, Exposure to CT, History of Pneumonia History of Tuberculosis, History of asthma, Exposure to Second hand smoking, Exposure to saw dust, Exposure to granite, Consumption of milk upto the age of 19 years Consumption of processed food up to 19 years, Consumption of processed food from 20-45 years.

${ }^{\mathrm{a}} \mathrm{GCE} \mathrm{O} / \mathrm{L}$ - General Certificate Examination of Ordinary Level

\section{Discussion}

Our study found that being an 'ever smoker' was a strong risk factor for lung cancer among males. Other significant risk factors for lung cancer identified in the multivariate logistic regression were, ever exposure to X-rays, educational level of GCE Ordinary Level or less and family history of cancer. The strength of adjusted risk of 'ever smokers' in the present study is comparable with European countries and is higher than the adjusted risk for lung cancer reported in other Asian countries [12-13]. One reason for this could be the high number of cigarettes smoked by the 'ever smokers' [12-13]. Young males in Western countries initiate smoking at very young age [14]. Early age at initiation of smoking is a strong risk factor for lung cancer [15]. According to data from the Colombo District if smoking among males could be prevented, $84 \%$ of lung cancers could be prevented.

\section{Funding}

This study was supported by a grant from Medical Research Institute, Colombo.

\section{Conflicts of interest}

There are no conflicts of interest.

\section{References}

1. World Health Organization. WHO global report on trends in prevalence of tobacco smoking 2015. Geneva: World Health Organization, 2015.

2. National Cancer Control Programme. Cancer Incidence Data Sri Lanka 2009. National Cancer Control Programme, Sri Lanka, 2015.

3. Edwards R. The problem of tobacco smoking. BMJ 2004; 328: 217-9.

4. Turner MC, Krewski D, Pope CA, 3rd, Chen Y, Gapstur SM, Thun MJ. Long-term ambient fine particulate matter air pollution and lung cancer in a large cohort of never-smokers. Am J Respir Crit Care Med 2011; 184: 1374-81.

5. Alberg AJ, Nonemaker J. Who is at high risk for lung cancer? Population-level and individual-level perspectives. Semin Respir Crit Care Med 2008; 29: 223-32.

6. Alberg AJ, Brock MV, Ford JG, Samet JM, Spivack SD. Epidemiology of lung cancer: Diagnosis and management of lung cancer, 3rd ed: American College of Chest Physicians evidence-based clinical practice guidelines. Chest 2013; 143: e1S-29S.

7. Bilello KS, Murin S, Matthay RA. Epidemiology, etiology, and prevention of lung cancer. Clinics in Chest Medicine 2002; 23: $1-25$.

8. Katulanda P, Wickramasinghe K, Mahesh JG, et al. Prevalence and correlates of tobacco smoking in Sri Lanka. Asia Pac J Public Health 2011; 23: 861-9.

9. Prasad R, Ahuja RC, Singhal S, et al. A case-control study of bidi smoking and bronchogenic carcinoma. Ann Thorac Med 2010; 5: 238-41.

10. Schoenborn CA, Adams PF, Peregoy JA. Health behaviors of adults: United States, 2008-2010. Vital Health Stat 2013; 10 .

11. Chulasiri PU, Gunawardena NS, Silva Ad. Prevalence and associated factors of smoking among adult males in Colombo district and cost of treatment of lung cancer attributed to smoking [unpublished MD dissertation]. Colombo: University of Colombo, Sri Lanka; 2015.

12. Hu J, Galeone C, Lui R, Pelucchi C, La Vecchia C, Negri E. Smoking and lung cancer in Harbin, northeast China. Ann Oncol 2005; 16: 1605-8.

13. Jee SH, Samet JM, Ohrr H, Kim JH, Kim IS. Smoking and cancer risk in Korean men and women. Cancer Causes Control 2004; 15: 341-8.

14. Stellman SD, Takezaki T, Wang L, et al. Smoking and lung cancer risk in American and Japanese men: an international case-control study. Cancer Epidemiol Biomarkers Prev 2001; 10: 1193-9.

15. Alberg AJ, Ford JG, Samet JM. Epidemiology of lung cancer: ACCP evidence-based clinical practice guidelines (2nd edition). Chest 2007; 132: 29s-55s. 